\title{
DHAGE ITERATION METHOD FOR APPROXIMATING SOLUTIONS OF NONLINEAR DIFFERENTIAL EQUATIONS WITH MAXIMA
}

\author{
BAPURAO C. DHAGE* AND DIANA OTROCOL** \\ *Kasubai, Gurukul Colony, Ahmepur-413515, Dist. Latur, Maharashtra, India \\ E-mail: bcdhage@gmail.com \\ ** Technical University of Cluj-Napoca, \\ Department of Mathematics, Memorandumului St. 28, 400114, Cluj-Napoca \\ "T. Popoviciu" Institute of Numerical Analysis \\ P.O.Box. 68-1, 400110 Cluj-Napoca, Romania \\ E-mail: dotrocol@ictp.acad.ro
}

\begin{abstract}
In this paper we study the initial value problem of first order nonlinear differential equations with maxima and discuss the existence and approximation of the solutions. The main result relies on the Dhage iteration method embodied in a recent hybrid fixed point theorem of Dhage (2014) in a partially ordered normed linear space. At the end, we give an example to illustrate the hypotheses and applicability of the abstract results of this paper.

Key Words and Phrases: Differential equations with maxima, Dhage iteration method, hybrid fixed point theorem, approximation of solutions.
\end{abstract}

2010 Mathematics Subject Classification: 34A12, 34A45, 47H07, 47H10.

Acknowledgment. The authors are thankful to Prof. I.A. Rus (Romania) and Dr. Shyam B. Dhage (India) for giving some suggestions for the improvement of this paper.

\section{REFERENCES}

[1] D.D. Bainov, S. Hristova, Differential Equations with Maxima, Chapman \& Hall/CRC Pure and Applied Mathematics, 2011.

[2] B.C. Dhage, Quadratic perturbations of periodic boundary value problems of second order ordinary differential equations, Differ. Equ. \& Appl., 2 (2010), 465-486.

[3] B.C. Dhage, Hybrid fixed point theory in partially ordered normed linear spaces and applications to fractional integral equations, Differ. Equ Appl., 5(2013), 155-184.

[4] B.C. Dhage, Partially condensing mappings in ordered normed linear spaces and applications to functional integral equations, Tamkang J. Math., 45(4)(2014), 397-426.

[5] B.C. Dhage, Nonlinear $\mathcal{D}$-set-contraction mappings in partially ordered normed linear spaces and applications to functional hybrid integral equations, Malaya J. Mat., 3(1)(2015), 62-85.

[6] B.C. Dhage, Operator theoretic techniques in the theory of nonlinear hybrid differential equations, Nonlinear Anal. Forum, 20(2015), 15-31. 
[7] B.C. Dhage, A new monotone iteration principle in the theory of nonlinear first order integrodifferential equations, Nonlinear Studies, 22(3)(2015), 397-417.

[8] B.C. Dhage, Some generalizations of a hybrid fixed point theorem in a partially ordered metric space and nonlinear functional integral equations, Differ. Equ Appl., 8(2016), 77-97.

[9] B.C. Dhage, S.B. Dhage, Approximating solutions of nonlinear first order ordinary differential equations, GJMS Special Issue for Recent Advances in Mathematical Sciences and Applications13, GJMS Vol., 2(2014), no. 2, 25-35.

[10] B.C. Dhage, S.B. Dhage, Approximating positive solutions of nonlinear first order ordinary quadratic differential equations, Cogent Mathematics, 2(2015), 1023671.

[11] B.C. Dhage, S.B. Dhage, S.K. Ntouyas, Approximating solutions of nonlinear hybrid differential equations, Appl. Math. Lett., 34(2014), 76-80.

[12] B.C. Dhage, S.B. Dhage, J.R. Graef, Dhage iteration method for initial value problems for nonlinear first order hybrid integrodifferential equations, J. Fixed Point Theory Appl., 17(2016), 309-325.

[13] S. Heikkilä and V. Lakshmikantham, Monotone Iterative Techniques for Discontinuous Nonlinear Differential Equations, Marcel Dekker Inc., New York 1994.

[14] J.J. Nieto, R. Rodriguez-Lopez, Contractive mappings theorems in partially ordered sets and applications to ordinary differential equations, Order, 22(2005), 223-239.

[15] D. Otrocol, Properties of the solutions of system of differential equations with maxima, via weakly Picard operator theory, Comm. in Applied Anal., 17(2013), no. 1, 99-107.

[16] D. Otrocol, Systems of functional differential equations with maxima, of mixed type, Electron. J. Qual. Theory Differ. Equ., 2014(2014), no. 5, 1-9.

[17] D. Otrocol, I.A. Rus, Functional-differential equations with "maxima" via weakly Picard operators theory, Bull. Math. Soc. Sci. Math. Roumanie, 51(99)(2008), no. 3, 253-261.

[18] D. Otrocol, I.A. Rus, Functional-differential equations with maxima of mixed type argument, Fixed Point Theory, 9(2008), no. 1, 207-220.

[19] A. Petruşel, I.A. Rus, Fixed point theorems in ordered L-spaces, Proc. Amer. Math. Soc., 134(2006), 411-418.

[20] A.C.M. Ran, M.C. Reurings, A fixed point theorem in partially ordered sets and some applications to matrix equations, Proc. Amer. Math. Soc., 132(2004), 1435-1443.

Received: January 23, 2016; Accepted: April 26, 2016. 